\title{
Traffic-related air pollution and alveolar nitric oxide in southern California children
}

\author{
Sandrah P. Eckel ${ }^{1}$, Zilu Zhang $^{1}$, Rima Habre ${ }^{1}$, Edward B. Rappaport ${ }^{1}$, \\ William S. Linn ${ }^{1}$, Kiros Berhane ${ }^{1}$, Yue Zhang ${ }^{2}$, Theresa M. Bastain ${ }^{1}$ and \\ Frank D. Gilliland ${ }^{1}$
}

\author{
Affiliations: \\ ${ }^{1}$ Dept of Preventive Medicine, University of Southern California, Los Angeles, CA, USA. \\ ${ }^{2}$ Dept of Internal Medicine, University of Utah, Salt Lake City, UT, USA.
}

\section{Correspondence:}

Sandrah P. Eckel, Dept of Preventive Medicine, University of Southern California, 2001 N. Soto Street, MC-9234, Los Angeles, CA 90089, USA.

E-mail: eckeldusc.edu

ABSTRACT Mechanisms for the adverse respiratory effects of traffic-related air pollution (TRAP) have yet to be established. We evaluated the acute effects of TRAP exposure on proximal and distal airway inflammation by relating indoor nitric oxide (NO), a marker of TRAP exposure in the indoor microenvironment, to airway and alveolar sources of exhaled nitric oxide $(\mathrm{FeNO})$.

FeNO was collected online at four flow rates in 1635 schoolchildren (aged 12-15 years) in southern California (USA) breathing NO-free air. Indoor NO was sampled hourly and linearly interpolated to the time of the FeNO test. Estimated parameters quantifying airway wall diffusivity (DawNO) and flux ( $J^{\prime}$ awNO) and alveolar concentration (CANO) sources of FeNO were related to exposure using linear regression to adjust for potential confounders.

We found that TRAP exposure indoors was associated with elevated alveolar NO. A 10 ppb higher indoor NO concentration at the time of the FeNO test was associated with $0.10 \mathrm{ppb}$ higher average CANO (95\% CI 0.04-0.16) (equivalent to a $7.1 \%$ increase from the mean), $4.0 \%$ higher $J$ 'awNO (95\% CI -2.8-11.3) and 0.2\% lower DawNO (95\% CI -4.8-4.6).

These findings are consistent with an airway response to TRAP exposure that was most marked in the distal airways.

@ERSpublications

Indoor exposure to traffic-related air pollution is associated with distal airway inflammation in schoolchildren http://ow.ly/V98mT

Editorial comment in: Eur Respir J 2016; 47: 1304-1306.

This article has supplementary material available from erj.ersjournals.com

Received: July 202015 | Accepted after revision: Nov 22 2015 | First published online: Jan 212016

Support statement: This work was supported by the National Heart, Lung and Blood Institute (grants 5R01HL61768 and 5R01HL76647); the Southern California Environmental Health Sciences Center (grant 5P30ES007048) funded by the National Institute of Environmental Health Sciences (NIEHS); the Children's Environmental Health Center (grants 5P01ES009581, R826708-01 and RD831861-01) funded by the NIEHS and the Environmental Protection Agency; the NIEHS (grants 5P01ES011627, 1R01ES023262-01 and 1K22ES022987); the James H. Zumberge Research and Innovation Fund; and the Hastings Foundation. Funding information for this article has been deposited with FundRef.

Conflict of interest: Disclosures can be found alongside the online version of this article at erj.ersjournals.com

Copyright OERS 2016 


\section{Introduction}

Traffic-related air pollution (TRAP) is an important urban exposure with adverse respiratory effects, but the mechanisms for these effects have yet to be established [1]. TRAP is a complex mixture of primary particulate matter and gaseous pollutants (e.g. nitrogen oxides $\left(\mathrm{NO}_{\mathrm{x}}\right)$ ) [1]. Typical TRAP exposure metrics include location-based measures, such as distance from roadways, or measurements of specific components, such as $\mathrm{NO}_{\mathrm{x}}$. In this article, we focus on nitric oxide (NO), a primary pollutant present in indoor and outdoor air, primarily from anthropogenic combustion sources (e.g. gas stoves and traffic) [2]. Once emitted, NO is rapidly oxidised and converted to nitrogen dioxide through photochemical processes or ozone $\left(\mathrm{O}_{3}\right)$ titration [2]. Outdoor NO concentrations display strong seasonal, diurnal and day-of-week patterns, with peaks coinciding with rush-hours, and high spatial variability, with concentrations decaying rapidly away from roadway sources [2]. Indoor NO depends on outdoor NO, air exchange rates and indoor emission/removal rates $[3,4]$. In the absence of indoor sources, indoor NO can be considered a marker of TRAP exposure in the indoor microenvironment [2].

The mechanisms of acute respiratory responses to TRAP exposure may be elucidated by studying the exhaled nitric oxide fraction ( $\mathrm{FeNO}$ ), a noninvasively assessed marker of lower respiratory tract inflammation endogenously produced in the airway and alveolar epithelium [5-7]. FeNO measured at the conventional $50 \mathrm{~mL} \cdot \mathrm{s}^{-1}$ exhalation flow rate $(F e N O 50)$ is responsive to both ambient air pollution (e.g. particles with a $50 \%$ cut-off aerodynamic diameter of $2.5 \mu \mathrm{m}$ (PM2.5), $10 \mu \mathrm{m}$ (PM10) and $\mathrm{O}_{3}$ ) and TRAP exposures [8-12]. When FeNO is measured at multiple flow rates (extended FeNO analysis), it can be partitioned into airway and alveolar sources, reflecting proximal airway inflammation and what is assumed to be distal inflammation, although confirmation by direct measurement is not available $[7,13]$.

Extended FeNO analysis can be used to study noninvasively the differential response of the proximal and distal airways to air pollution exposures. To our knowledge, there has been only one such study. MoDIG et al. [14] related low and high flow FeNO in adults to short-term averages of central site ambient air pollution. However, low and high flow FeNO are imperfect proxies for airway and alveolar NO [15] and it remains unknown whether short-term TRAP exposures have differential associations with proximal and distal lower respiratory tract inflammation in children. We hypothesise that there will be differential proximal and distal airway inflammatory responses to TRAP exposure, possibly due to ultrafine particles (UFPs), which are an important component of the TRAP mixture and have a larger deposition profile in the distal airways. Exposures to UFPs from traffic sources are difficult to assess directly. Measurement of NO concentrations, which are strongly correlated to traffic-related UFPs, offers a practical alternative method for exposure assessment [16].

FeNO concentrations are in the parts-per-billion range, so specific precautions, as described in the American Thoracic Society (ATS)/European Respiratory Society (ERS) recommendations [17] are required to avoid contamination with room air NO. For online measurement of $F$ eNO at a fixed flow rate, inhalation of air with a high NO concentration produces an early peak in FeNO from mixed expiratory air, but the subsequent steady-state plateau concentration is thought to be unaffected by ambient NO concentrations due to the fast uptake of inhaled NO by haemoglobin in the pulmonary capillary blood [17, 18]. Inhalation of NO-free air for two or more tidal breaths before the FeNO test precludes the early peak. Earlier work in the southern California Children's Health Study (CHS) showed that offline FeNO was associated with room air NO, but online FeNO50 in the same children was not [19].

The goal of this study was to investigate the association between short-term exposure to TRAP and localised lower respiratory tract inflammation. Using cross-sectional data from the CHS, a population-based cohort study of schoolchildren, we examined the association of schoolroom indoor NO with no known indoor sources of $\mathrm{NO}$ (as a marker for exposure to TRAP in the indoor microenvironment) with airway and alveolar sources of NO estimated from online extended FeNO analysis in children breathing NO-free air.

\section{Methods}

\section{Study population}

Participants were children from a CHS cohort originally recruited in 2002-2003 from kindergarten or first-grade classrooms in southern California [20]. We included data from the 1635 children in eight communities who participated in the first year of extended FeNO assessment (from March to June 2010, with each community visited in two or three separate rounds) [21] and who returned the corresponding annual written questionnaire. Written informed consent was obtained from a parent/guardian on behalf of each child participant. The study protocol was approved by the University of Southern California Health Sciences Campus institutional review board. 


\section{Extended FeNO collection}

FeNO was assessed online using three chemiluminescence analysers (model CLD88-SP with DeNOx accessory to provide NO-scrubbed air; EcoMedics, Duernten, Switzerland/Ann Arbor, MI, USA) in a protocol described previously [21-23]. Briefly, children were requested to perform nine FeNO manoeuvres, in the following order: three at the conventional $50 \mathrm{~mL} \cdot \mathrm{s}^{-1}$ target flow rate and two at each of the following target flow rates: 30,100 and $300 \mathrm{~mL} \cdot \mathrm{s}^{-1}$. Immediately prior to each manoeuvre, the child breathed through a DeNOx scrubber for two or more tidal breaths followed by inhalation to total lung capacity and exhalation at the target flow rate. As described in greater detail in the online supplementary material, DeNOx zero checks were performed twice daily and FeNO data processing was based on the ATS/ERS guidelines for FeNO at $50 \mathrm{~mL} \cdot \mathrm{s}^{-1}$ [17] and an airway turnover search window [24]. FeNO50 and FeNO300 were calculated as the average of reproducible manoeuvres at $50 \mathrm{~mL} \cdot \mathrm{s}^{-1}$ and $300 \mathrm{~mL} \cdot \mathrm{s}^{-1}$, respectively.

\section{Assessing indoor TRAP exposure using indoor NO measurements}

FeNO was tested in empty schoolrooms with no known sources of NO. Indoor NO was measured approximately hourly, using the FeNO analysers, in the FeNO testing room. For each analyser, indoor NO values were linearly interpolated to the time of each participant's first FeNO manoeuvre and the interpolated value was used as the indoor TRAP exposure metric. Unanticipated sources of indoor NO were noted in field logs. We compared diurnal variation in test room NO to hourly ambient NO from central site monitors located in each community (online supplementary figs E1 and E2).

\section{NO parameter estimation}

The two-compartment model of NO in the lower respiratory tract [7] describes FeNO as a function of flow rate and three "NO parameters": alveolar NO concentration (CANO), maximum airway wall NO flux $\left(J^{\prime}\right.$ awNO) and airway wall tissue diffusing capacity (DawNO). As described in the online supplementary material, we estimated these NO parameters for each participant using a multilevel modelling extension [25] of the participant-specific nonlinear least squares model proposed by ECKEL et al. [26]. For sensitivity analysis, we estimated NO parameters using the Högman and Meriläinen algorithm (HMA) [27] modified for CHS data [21, 26], which omits internal data checks found to bias NO parameter estimation [26].

\section{Data analysis}

For clarity of exposition, we collectively refer to the estimated NO parameters, FeNO50 and FeNO300 as "extended FeNO summaries". We group them into summaries thought to reflect, to a greater extent, NO from proximal (FeNO50, J'awNO and DawNO) or distal (FeNO300 and CANO) airway sources. We related indoor NO exposure to each of the extended FeNO summaries using multiple linear regression models to adjust for potential confounders (age, sex, race/ethnicity, rhinitis history, ever report of doctor-diagnosed asthma, use of asthma medications in the past 12 months, secondhand tobacco smoke exposure, highest attained parental education, time of FeNO test, FeNO analyser and CHS community). To better satisfy modelling assumptions, FeNO50, J'awNO, DawNO and FeNO300 were natural log transformed. CANO was analysed without transformation. Sensitivity analyses included additional adjustment for longer-term time trends (either a four degrees of freedom natural cubic spline of test date or indicators of community-specific rounds of FeNO assessment) and various data exclusions. We evaluated evidence for modification of indoor NO exposure associations by asthma by including a multiplicative interaction term. We also considered single lag models with indoor NO lagged 0, 30 or $60 \mathrm{~min}$ and used the Akaike information criterion (AIC) [28] to select the best fitting model. All hypothesis tests were two-sided, with a significance level of 0.05. Analyses were performed using R version 3.1.0 [29].

\section{Results}

Participants were aged between 12 and 15 years old; more than half identified as Hispanic white (58.2\%); most had some history of rhinitis (38.1\% not current and $31.5 \%$ current); and 321 (19.6\%) reported a physician diagnosis of asthma, of whom 48 reported taking inhaled corticosteroid medication in the past 12 months (table 1). The geometric means of FeNO50, J'awNO, DawNO and FeNO300 were $15.4 \mathrm{ppb}$, $876 \mathrm{pL} \cdot \mathrm{s}^{-1}, 18.8 \mathrm{pL} \cdot \mathrm{s}^{-1} \cdot \mathrm{ppb}^{-1}$ and $4.2 \mathrm{ppb}$, respectively. Mean CANO was $1.4 \mathrm{ppb}$. Table 2 shows that log FeNO50 was highly correlated with $\log J^{\prime}$ awNO (Pearson's $\mathrm{R}=0.97$ ), as has been recognised previously [26]. Notably, $\log$ FeNO300 was more highly correlated with proximal airway NO ( $\mathrm{R}=0.93$ for $\log J^{\prime}$ awNO and $\mathrm{R}=0.96$ for $\log \mathrm{FeNO} 50)$ than with alveolar $\mathrm{NO}$ ( $\mathrm{R}=0.69$ for CANO).

Indoor $\mathrm{NO}$ concentrations at the time of the FeNO test, our marker for indoor exposure to TRAP, ranged from 0.0 to $58.5 \mathrm{ppb}$ (table 3). Most children (67.0\%) had FeNO tested after 10:00 h, when indoor NO tended to be lower following the peaks from morning rush-hour and school drop-offs. On many testing dates, the diurnal patterns of indoor $\mathrm{NO}$ and outdoor $\mathrm{NO}$ at the community's central site monitor were similar, reflecting high (i.e. $\sim$ ) outdoor-to-indoor infiltration rates and common meteorology (online 
TABLE 1 Extended exhaled nitric oxide fraction ( $F_{\mathrm{eNO}}$ ) summaries, demographic characteristics and potential confounders in 1635 Children's Health Study participants

\begin{tabular}{|c|c|}
\hline FeNO50 $\mathrm{ppb}^{\pi}$ & $15.4 \pm 2.1$ \\
\hline Data missing & 3.0 \\
\hline$J^{\prime}$ awNO $\mathrm{pL} \cdot \mathrm{s}^{-1 \#, \uparrow}$ & $875.6 \pm 2.3$ \\
\hline DawNO $\mathrm{pL} \cdot \mathrm{s}^{-1} \cdot \mathrm{ppb}^{-1 \#, \uparrow}$ & $18.8 \pm 1.8$ \\
\hline FeN0300 ppb & $4.2 \pm 2.0$ \\
\hline Data missing & 16.6 \\
\hline CANo ppb" & $1.4 \pm 0.7$ \\
\hline Age years & $13.4 \pm 0.6$ \\
\hline Male & 48.7 \\
\hline Body mass index percentile & $61.9 \pm 30.3$ \\
\hline Data missing & 0.3 \\
\hline \multicolumn{2}{|l|}{ Race/ethnicity } \\
\hline White/non-Hispanic & 30.9 \\
\hline Hispanic & 58.2 \\
\hline Black & 1.7 \\
\hline Asian/Hawaiian/Pacific Islander & 4.1 \\
\hline Other & 4.7 \\
\hline Data missing & 0.4 \\
\hline \multicolumn{2}{|l|}{ Parent education } \\
\hline Up to 12 th grade & 19.7 \\
\hline Completed 12 th grade & 15.5 \\
\hline Beyond 12 th grade & 58.7 \\
\hline Data missing & 6.1 \\
\hline \multicolumn{2}{|l|}{ Rhinitis history } \\
\hline Never & 30.4 \\
\hline No current & 38.1 \\
\hline Current & 31.5 \\
\hline Asthma & 19.6 \\
\hline \multicolumn{2}{|c|}{ Asthma medication use, in the 321 children with asthma ${ }^{+}$} \\
\hline None & 63.2 \\
\hline Rescue only & 18.4 \\
\hline Control only & 2.8 \\
\hline Rescue and control & 14.3 \\
\hline Data missing & 1.2 \\
\hline Exposed to secondhand smoke & 8.4 \\
\hline \multicolumn{2}{|l|}{ Time of $F$ eNo test } \\
\hline $07: 00-9: 59 \mathrm{~h}$ & 33.0 \\
\hline $10: 00-11: 59 h$ & 40.7 \\
\hline $12: 00-16: 07 \mathrm{~h}$ & 26.3 \\
\hline
\end{tabular}

Data are presented as mean \pm SD or \%, unless otherwise stated. FeNOx: FeNO measured at an exhalation flow rate of $x \mathrm{~mL} \cdot \mathrm{s}^{-1}$; J'awNo: maximum airway wall nitric oxide flux; Dawno: diffusing capacity of the airway wall tissue for nitric oxide; CANO: alveolar nitric oxide concentration. "\#: estimated population-level values from the mixed effects regression model used to estimate the nitric oxide parameters; ${ }^{\text {n: }}$ geometric mean $\pm \mathrm{SD} ;{ }^{+}$: of children without parent report of doctor-diagnosed asthma, eight reported taking rescue medication only, five took control medication only, four took both and 18 were missing a response to this question.

TABLE 2 Pearson's correlations of the extended exhaled nitric oxide fraction $\left(F_{\mathrm{eNO}}\right)$ summaries

\begin{tabular}{|c|c|c|c|c|c|}
\hline & $\log F_{\mathrm{eN}} 050$ & $\log J^{\prime}$ awNo & $\log$ Dawno & $\log F_{\mathrm{eN} 0300}$ & CANO \\
\hline $\log \mathrm{FeNO}_{50}$ & 1.00 & & & & \\
\hline $\log J^{\prime}$ awNo & 0.97 & 1.00 & & & \\
\hline log Dawno & 0.38 & $0.51^{\#}$ & 1.00 & & \\
\hline $\log \mathrm{FeNO}_{300}$ & 0.96 & 0.93 & 0.34 & 1.00 & \\
\hline CANO & 0.49 & $0.21^{\#}$ & $-0.41^{\#}$ & 0.69 & 1.00 \\
\hline \multicolumn{6}{|c|}{$\begin{array}{l}\text { FeNOx: FeNO measured at an exhalation flow rate of } x \mathrm{~mL} \cdot \mathrm{s}^{-1} ; J^{\prime} \text { awNO: maximum airway wall nitric oxide flux; } \\
\text { DawnO: diffusing capacity of the airway wall tissue for nitric oxide; CANO: alveolar nitric oxide concentration. } \\
\# \text { : correlations of nitric oxide (NO) parameters are calculated from the estimated variance/covariance } \\
\text { matrix of the random effects in the nonlinear mixed effects model used to estimate NO parameters. }\end{array}$} \\
\hline
\end{tabular}


TABLE 3 Distribution of indoor nitric oxide (NO) interpolated to the time of the exhaled nitric oxide fraction ( $F$ eNO) test, overall and by categorised hour of FeNO collection

\begin{tabular}{lccccccc} 
& Min & \multicolumn{3}{c}{ Percentile } & Max \\
\cline { 3 - 7 } & & 5th & 25th & 50th & 75th & 95th & \\
\hline Overall & 0.0 & 0.1 & 0.7 & 1.9 & 4.3 & 13.4 & 58.5 \\
$\mathbf{0 7 : 0 0 - 0 9 : 5 9 ~ h ~}$ & 0.0 & 0.3 & 1.4 & 3.3 & 6.3 & 14.1 & 58.5 \\
$\mathbf{1 0 : 0 0 - 1 1 : 5 9 ~ h ~}$ & 0.0 & 0.1 & 0.6 & 1.9 & 4.4 & 18.4 & 41.4 \\
$\mathbf{1 2 : 0 0 - 1 6 : 0 7 ~} \mathbf{~}$ & 0.0 & 0.0 & 0.4 & 1.0 & 2.2 & 4.5 & 15.8 \\
\hline
\end{tabular}

supplementary figure E2). On March 17 and 18, 2010 in Mira Loma, the two dates with highest indoor $\mathrm{NO}$, the diurnal patterns of schoolroom indoor NO and central site NO were similar.

We found robust evidence for an association of TRAP exposure in the indoor microenvironment, as assessed by indoor NO, with FeNO from distal sources (CANO and FeNO300). Associations were less consistent with $F$ eNO from proximal sources. After adjusting for potential confounders (tables 4 and 5 and online supplementary tables E1 and E2), a $10 \mathrm{ppb}$ higher indoor NO concentration was significantly associated with $0.10 \mathrm{ppb}(95 \% \mathrm{CI} 0.04-0.16 \mathrm{ppb}$ ) higher average CANO (equivalent to a $7.1 \%$ increase from the mean of $1.4 \mathrm{ppb}$ to $1.5 \mathrm{ppb}$ ) and 6.5\% (95\% CI 0.3-13.1\%) higher FeNO300 and nonsignificantly associated with $2.8 \%$ (95\% CI -3.3-9.3\%) higher FeNO50, 4.0\% (95\% CI -2.8-11.3\%) higher J'awNO and $0.2 \%$ (95\% CI $-4.8-4.6 \%$ ) lower DawnO. The CANO results were robust to various sensitivity analyses, including adjustment for longer-term time trends, exclusion of the aforementioned potentially influential dates with high indoor NO (Mira Loma; March 17 and 18, 2010) and using HMA estimation of NO parameters (tables 4 and 5 and online supplementary tables E3-E5).

Children with asthma had larger estimated effects of indoor NO for all extended FeNO summaries except Dawno (figure 1), although none of the differences in effects comparing children with asthma to those without were statistically significant (interaction p-values all $\geqslant 0.22$ ).

Associations of lagged indoor NO (up to $1 \mathrm{~h}$ prior to the FeNO test) with CANO were estimated in the subset of 1212 children tested $\geqslant 1 \mathrm{~h}$ after the first test of the day for each analyser. Since indoor NO was only measured during FeNO testing, the 423 children tested within the first hour were excluded. The bestfitting model, by minimum AIC, used a 60 min lag (table 6) and estimated that a $10 \mathrm{ppb}$ higher indoor NO concentration $60 \mathrm{~min}$ prior was associated with $0.12 \mathrm{ppb}$ (95\% CI $0.05-0.19 \mathrm{ppb}$ ) higher average CANO. Considering lags up to $2 \mathrm{~h}$ (and hence restricting the analysis even further to the $\mathrm{n}=811$ children tested $\geqslant 2 \mathrm{~h}$ after the first test) produced slightly attenuated effect estimates and found that a model with 30-min lag had the smallest AIC (online supplementary table E6).

\section{Discussion}

This study investigated the association between short-term TRAP exposures in the indoor microenvironment, assessed using indoor NO, and regional lower respiratory tract inflammation based on extended FeNO analysis,

TABLE 4 Estimated percentage difference in each "proximal airway" extended exhaled nitric oxide fraction (FeNo) summary associated with a $10 \mathrm{ppb}$ increase in indoor nitric oxide at the time of the FeNO test, for several linear regression models

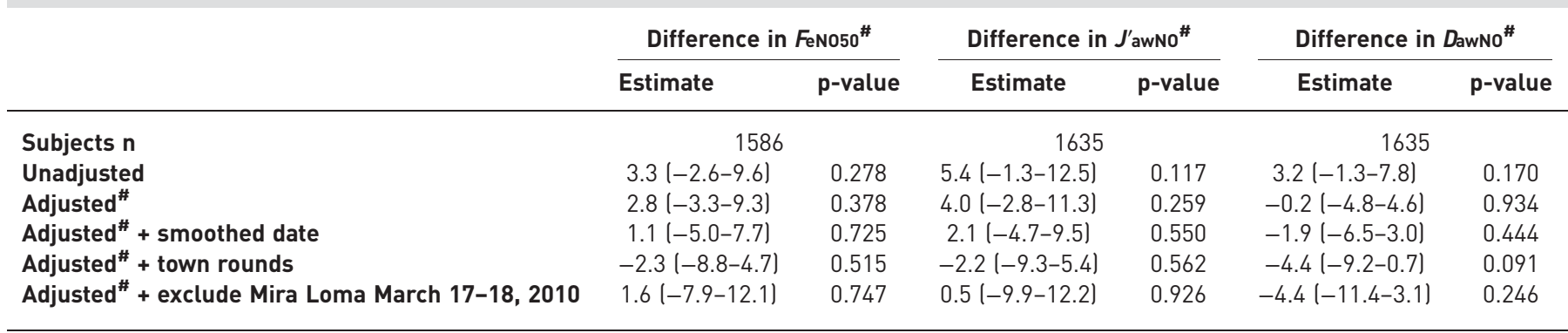

Data are presented as $\%$ difference $(95 \% \mathrm{CI})$, unless otherwise stated. FeN050: FeNO measured at an exhalation flow rate of $50 \mathrm{~mL} \cdot \mathrm{s}^{-1}$; $\mathrm{J}^{\prime}$ awNO: maximum airway wall nitric oxide flux; Dawno: diffusing capacity of the airway wall tissue for nitric oxide. ${ }^{\#}$ : adjustment covariates: age, sex, race/ethnicity, rhinitis history, ever report of doctor-diagnosed asthma, use of asthma medications in the past 12 months, secondhand tobacco smoke exposure, highest attained parental education, time of FeNO test, Feno analyser and Children's Health Study community. 
TABLE 5 Estimated difference in each "distal airway" extended exhaled nitric oxide fraction (FeNo) summary associated with a $10 \mathrm{ppb}$ increase in indoor nitric oxide at the time of the FeNO test, for several linear regression models

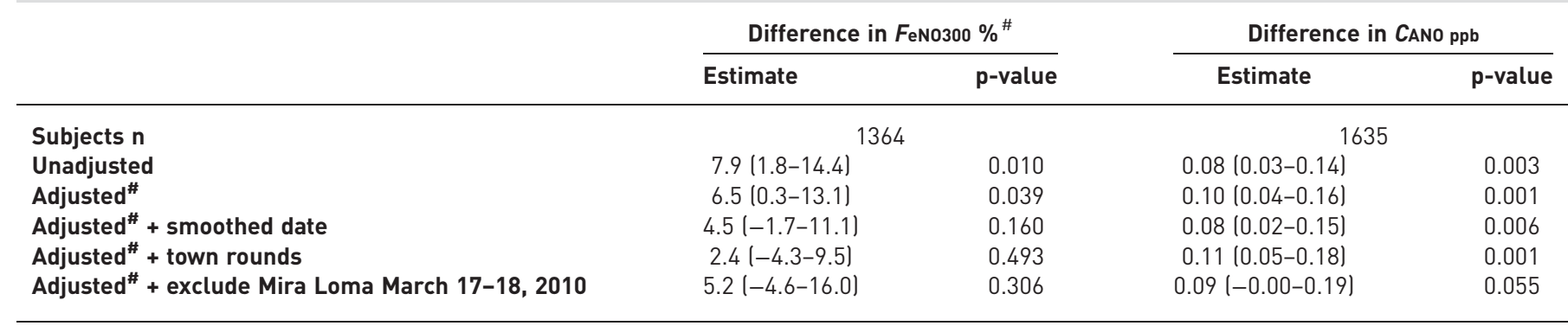

Data are presented as difference $(95 \% \mathrm{Cl})$, unless otherwise stated. FeNO300: $F_{\text {eNO }}$ measured at an exhalation flow rate of $300 \mathrm{~mL} \cdot \mathrm{S}^{-1}$; $\mathrm{CANO}_{\mathrm{ANO}}$ alveolar nitric oxide concentration. \#: adjustment covariates: age, sex, race/ethnicity, rhinitis history, ever report of doctor-diagnosed asthma, use of asthma medications in the past 12 months, secondhand tobacco smoke exposure, highest attained parental education, time of Feno test, FeNO analyser and Children's Health Study community.

in a large population-based cohort of schoolchildren. We found strong evidence for a positive association of indoor exposures to TRAP with FeNO from distal sources (CANO and FeNO300) in schoolchildren. Lagging indoor NO by 30-60 min slightly improved model fit, providing biological plausibility for our hypothesis of an acute distal airway inflammatory response. There was some (nonsignificant) evidence to support an association of indoor exposures to TRAP with FeNO from proximal sources (FeNO50 and $J^{\prime}$ awNO, but not DawNO) in children with asthma, similar to previous studies of TRAP and FeNO50 [11]. We speculate that the observed pattern of associations may potentially be due to higher deposition of UFPs, a toxic component of TRAP, typically strongly correlated with $\mathrm{NO}$, in distal versus proximal airways. We did not measure traffic-related or total UFPs in our study, so this should be investigated in future work.

To our knowledge, extended FeNO analysis has been used in no studies of TRAP and in only one study of the respiratory health effects of ambient air pollution in adults, by Modig et al. [14]. Modig et al. [14] related FeNO50 and FeNO270 measured in 5841 adults to short-term averages of measurements of $\mathrm{O}_{3}, \mathrm{NO}_{\mathrm{x}}$, and PM10 from a central site location. In multipollutant models, the authors found significant associations of both 120-h average $\mathrm{O}_{3}$ and 24-h average $\mathrm{NO}_{\mathrm{x}}$ with distal airway $\mathrm{NO}$ and less evidence for associations with proximal airway NO [30]. Specifically, an interquartile range (IQR) increase in $\mathrm{O}_{3}$ was associated with a $5.1 \%(95 \%$ CI $1.7-8.5 \%)$ increase in $\mathrm{FeNO} 270$ and a $3.6 \%$ (95\% CI -0.1-7.5\%) increase in FeNO50, while an IQR increase in $\mathrm{NO}_{\mathrm{x}}$ was associated with a $1.4 \%$ (95\% CI $\left.0.1-2.8 \%\right)$ increase in FeNO270 and a $0.2 \%$ (95\% CI $-1.3-1.7 \%$ ) increase in FeNO50 [14]. In our data, log FeNO300 was more highly correlated with airway wall NO than with alveolar NO, highlighting the problem of using high-flow FeNO as a proxy
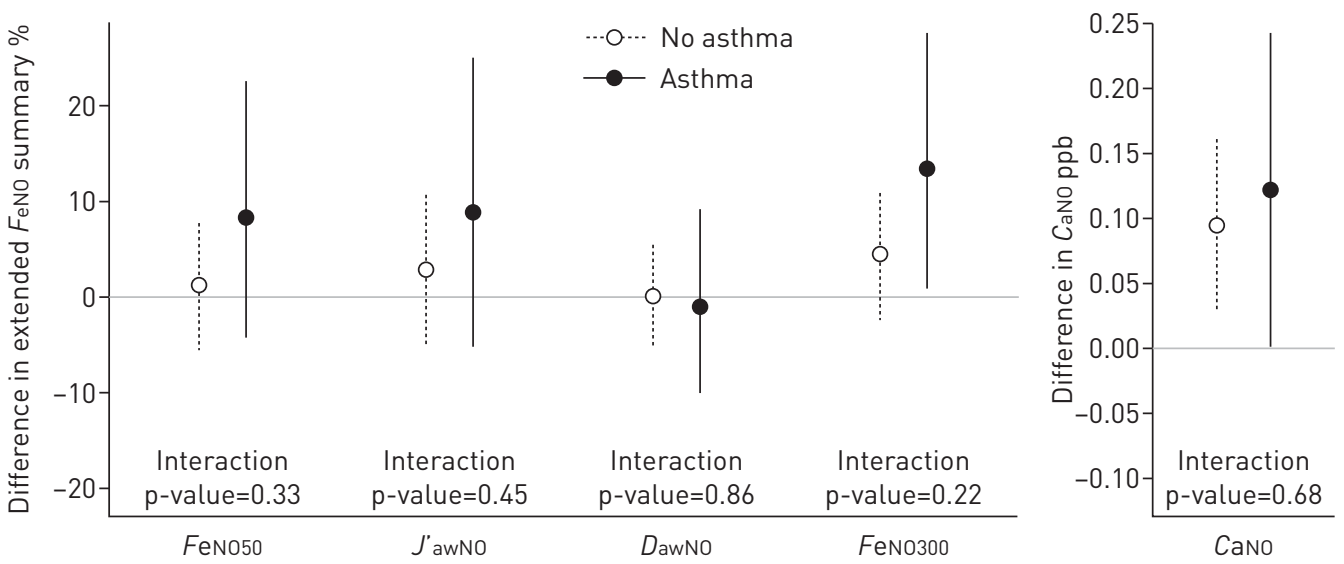

FIGURE 1 Asthma-specific estimated differences $(95 \% \mathrm{CI})$ in each extended exhaled nitric oxide fraction ( $\left.F_{\mathrm{eNO}}\right)$ summary associated with a $10-\mathrm{ppb}$ increase in indoor nitric oxide (NO) at the time of the FeNO test from models with an interaction between asthma and indoor NO. Data were adjusted for age, sex, race/ethnicity, rhinitis history, use of asthma medications in the past 12 months, secondhand tobacco smoke exposure, highest attained parental education, time of $F_{\mathrm{eNO}}$ test, $F_{\mathrm{eNO}}$ analyser and Children's Health Study community. FeNOx: FenO measured at an exhalation flow rate of $x \mathrm{~mL} \cdot \mathrm{s}^{-1} ; J^{\prime}$ awNO: maximum airway wall nitric oxide flux; DawNO: diffusing capacity of the airway wall tissue for nitric oxide; CANO: alveolar nitric oxide concentration. 
TABLE 6 Difference in alveolar nitric oxide (NO) concentration associated with a $10 \mathrm{ppb}$ increase in indoor NO 0, 30 or 60 min before the exhaled NO fraction ( $F$ eNO) test, from single-lag models adjusted for potential confounders

\begin{tabular}{lccc} 
Lag of room air N0 $\min$ & Estimate $(\mathbf{9 5 \%} \mathrm{Cl})$ & p-value & AIC \\
\hline $\mathbf{0}$ & $0.14(0.04-0.24)$ & 0.004 & 2619.2 \\
$\mathbf{3 0}$ & $0.14(0.05-0.22)$ & 0.001 & 2617.3 \\
$\mathbf{6 0}$ & $0.12(0.05-0.19)$ & $<0.001$ & $\mathbf{2 6 1 5 . 5}$ \\
\hline
\end{tabular}

Models are fit to the subset of $n=1212$ children tested at least an hour after the first $F_{\text {eNO }}$ test of the day. Adjustment covariates: age, sex, race/ethnicity, rhinitis history, ever report of doctor-diagnosed asthma, use of asthma medications in the past 12 months, secondhand tobacco smoke exposure, highest attained parental education, time of FeNO test, FeNO analyser and Children's Health Study community. AlC: Akaike information criterion.

for alveolar NO [15]. We expect that Modig et al. [14] would have observed clearer, more differential associations had they conducted extended FeNO modelling to partition multiple flow FeNO into proximal $\left(J^{\prime}\right.$ awNO) and distal (CANO) sources.

TRAP has been related to FeNO at a single exhalation flow rate in other studies, many having larger exposure contrasts than our study. From repeat tests on 18 subjects breathing NO-free air, offline FeNO was on average $73 \%$ higher $(\mathrm{p}<0.001)$ on days when outdoor NO was high $\left(246 \mu \mathrm{g} \cdot \mathrm{m}^{-3}\right)$ versus low $\left(3.6 \mu \mathrm{g} \cdot \mathrm{m}^{-3}\right.$ ) [31]. In 29 nonsmoking elderly subjects breathing NO-free air, an $11.9 \mathrm{ppb}$ increase in $24 \mathrm{~h}$ average central site NO (maximum $70.7 \mathrm{ppb}$ ) was associated with a $0.83 \mathrm{ppb}$ (95\% CI $0.26-1.40 \mathrm{ppb}$ ) increase in offline FeNO [32]. A crossover study of 28 healthy adults walking for $2 \mathrm{~h}$ in low and high traffic pollution sites (at the high traffic site $\mathrm{NO}_{\mathrm{x}}$, black carbon and UFP number were 5-10-fold higher and highly correlated $(>0.9)$ ) found that exposure to high TRAP was associated with a $0.89 \mathrm{ppb}$ increase in FeNO, with the maximum mean increase in FeNO at $30 \mathrm{~min}$ post-exposure [33]. In 57 adult asthmatics followed for 6 months, daily mean ambient UFP number concentration and NO were strongly correlated (Spearman's R 0.73-0.77) and UFP number concentrations had the strongest negative associations with daily peak expiratory flow measurements [34]. Particularly relevant to our motivating hypothesis, a study of 103 schoolchildren found strong associations of personal daily alveolar deposited UFP surface area with forced expiratory flow at $25-75 \%$ of forced vital capacity (negative association in all children, $\mathrm{R}^{2}=0.1$ ) and FeNO50 (positive association, only in the 16 children with asthma, $\mathrm{R}^{2}=0.9$ ) [35].

Strengths of this study include the large population-based cohort of schoolchildren, the online measurement of FeNO at multiple flow rates using sensitive chemiluminescence analysers [36] by trained field technicians using a rigorous protocol requiring two or more tidal breaths through a DeNOx scrubber (zero-checked twice daily) prior to each manoeuvre [17], and the use of a highly temporally and spatially resolved exposure metric for TRAP (indoor NO). Statistical estimation of NO parameters allowed for better separation of proximal and distal sources of NO than average FeNO from low and high target flow rates [15]. The ECKEL et al. [26] method for estimating NO parameters has been shown to have good statistical properties and the mixed-effects modelling extension of this approach [25] borrows strength across participants to produce NO parameter estimates for all participants. Participant-specific models typically fail to produce NO parameter estimates for a subset of participants. Exclusion of these participants from subsequent analyses could bias results. Finally, the observed CANO association was robust in a wide array of sensitivity analyses.

This study has several limitations. The two-compartment model of NO assumes inhalation of NO-free air and that blood is an infinite sink for NO [37], ignoring any possible change in the production or consumption rates of $\mathrm{NO}$ in the tissue or in the ability of NO to bind to haemoglobin due to prolonged inhalation of air with elevated NO concentrations. However, in our study children breathed NO-scrubbed air and indoor NO was relatively low $(<58.5 \mathrm{ppb})$. Additionally, indoor $\mathrm{NO}$ measurements are an imperfect surrogate for exposure to TRAP. Indoor NO measurements reflect the indoor environment where children spend time and are more spatially and temporally resolved than many common TRAP exposure metrics (e.g. central site measurements or distance to nearest major road), but they are not measurements of personal exposure. In our study, we expect that outdoor-to-indoor infiltration rates were high (i.e. 1). A typical testing session was conducted in an otherwise empty classroom, with no indoor source of NO, that opened to the outdoors (as is common in southern California), with the door left propped open to welcome the next child to be tested. Finally, because indoor NO was assessed by FeNO analysers only during testing sessions, lagged indoor NO (e.g. a 1-h lag) was available only in a subset of 
children, resulting in reduced power to detect an association due to reduced sample size and reduced exposure variability (excluded children were tested earlier, when NO tended to be highest).

Our results should also be interpreted in the context of the considerable body of literature investigating whether room air NO contaminates FeNO samples. All studies that failed to find an association used online FeNO measurement $[18,38-41]$. Studies that found an association used offline FeNO sampling methods in participants breathing room air (e.g. as in [42]) or early online methods for FeNO measurement (e.g. as in [43]). In the first year of online FeNO measurement in the CHS, 386 children provided both online FeNO (breathing through a DeNOx scrubber) and offline FeNO (breathing through the offline test kit NO scrubber, with deadspace air discarded) [19]. We found that online FeNO was not associated with test indoor NO (Pearson's $\mathrm{R}=0.09, \mathrm{p}=0.08$ ) while offline FeNO was $(\mathrm{R}=0.30, \mathrm{p}<0.0001$ ), primarily due to incomplete removal of $\mathrm{NO}$ by the offline scrubber and residual contamination [19].

In conclusion, TRAP exposure in the indoor microenvironment, assessed using indoor NO, was associated with exhaled NO from alveolar sources in schoolchildren. CANO concentration differences were small but robust, consistent with an acute distal airway inflammatory response to TRAP exposures. Future studies could refine exposure assessment (e.g. personal exposure measurements) and study a larger sample of children with asthma.

\section{Acknowledgements}

The authors gratefully acknowledge the contributions of Children's Health Study participants and the exhaled nitric oxide fraction field team: Steve Howland, Ned Realiza and Lisa Valencia (Dept of Preventive Medicine, University of Southern California, Los Angeles, CA, USA).

\section{References}

1 Guarnieri M, Balmes JR. Outdoor air pollution and asthma. Lancet 2014; 383: 1581-1592.

2 Lazarus SC, Drechsler DM. The Health Impact of Nitric Oxide: Effects on Lung Function and Cellular and Biochemical Processes in Healthy Humans. Sacramento, California Air Resources Board Research Division, 2001.

3 Nazaroff WW, Cass GR. Mathematical modeling of chemically reactive pollutants in indoor air. Environ Sci Technol 1986; 20: 924-934.

4 Weschler CJ. Ozone in indoor environments: concentration and chemistry. Indoor Air 2000; 10: $269-288$.

5 Barnes PJ, Dweik RA, Gelb AF, et al. Exhaled nitric oxide in pulmonary diseases: a comprehensive review. Chest 2010; 138: 682-692.

6 Bucca C, Cicolin A, Guida G, et al. Exhaled nitric oxide (FENO) in non-pulmonary diseases. J Breath Res 2012; 6: 027104.

7 George SC, Hogman M, Permutt S, et al. Modeling pulmonary nitric oxide exchange. J Appl Physiol 2004; 96: 831-839.

8 La Grutta S, Ferrante G, Malizia V, et al. Environmental effects on fractional exhaled nitric oxide in allergic children. J Allergy 2012; 2012: 916926.

9 Scarpa MC, Kulkarni N, Maestrelli P. The role of non-invasive biomarkers in detecting acute respiratory effects of traffic-related air pollution. Clin Exp Allergy 2014; 44: 1100-1118.

10 Berhane K, Zhang Y, Salam MT, et al. Longitudinal effects of air pollution on exhaled nitric oxide: the Children's Health Study. Occup Environ Med 2014; 71: 507-513.

11 Eckel SP, Berhane K, Salam MT, et al. Residential traffic-related pollution exposures and exhaled nitric oxide in the Children's Health Study. Environ Health Perspect 2011; 119: 1472-1477.

12 Delfino RJ, Staimer N, Tjoa T, et al. Airway inflammation and oxidative potential of air pollutant particles in a pediatric asthma panel. J Expo Sci Environ Epidemiol 2013; 23: 466-473.

13 Korevaar DA, Westerhof GA, Wang J, et al. Diagnostic accuracy of minimally invasive markers for detection of airway eosinophilia in asthma: a systematic review and meta-analysis. Lancet Respir Med 2015; 3: 290-300.

14 Modig L, Dahgam S, Olsson D, et al. Short-term exposure to ozone and levels of exhaled nitric oxide. Epidemiology 2014; 25: 79-87.

15 Eckel SP, Salam MT. Single high flow exhaled nitric oxide is an imperfect proxy for distal nitric oxide. Occup Environ Med 2013; 70: 519-520.

$16 \mathrm{Hu}$ S, Fruin S, Kozawa K, et al. A wide area of air pollutant impact downwind of a freeway during pre-sunrise hours. Atmos Environ 2009; 43: 2541-2549.

17 American Thoracic Society/European Respiratory Society. ATS/ERS recommendations for standardized procedures for the online and offline measurement of exhaled lower respiratory nitric oxide and nasal nitric oxide, 2005. Am J Respir Crit Care Med 2005; 171: 912-930.

18 Silkoff PE, McClean PA, Slutsky AS, et al. Marked flow-dependence of exhaled nitric oxide using a new technique to exclude nasal nitric oxide. Am J Respir Crit Care Med 1997; 155: 260-267.

19 Linn WS, Berhane KT, Rappaport EB, et al. Relationships of online exhaled, offline exhaled, and ambient nitric oxide in an epidemiologic survey of schoolchildren. J Expo Sci Environ Epidemiol 2009; 19: 674-681.

20 McConnell R, Berhane K, Yao L, et al. Traffic, susceptibility, and childhood asthma. Environ Health Perspect 2006; 114: 766-772.

21 Linn WS, Rappaport EB, Eckel SP, et al. Multiple-flow exhaled nitric oxide, allergy, and asthma in a population of older children. Pediatr Pulmonol 2013; 48: 885-896.

22 Linn WS, Rappaport EB, Berhane KT, et al. Extended exhaled nitric oxide analysis in field surveys of schoolchildren: a pilot test. Pediatr Pulmonol 2009; 44: 1033-1042.

23 Islam T, Urman R, Gauderman WJ, et al. Parental stress increases the detrimental effect of traffic exposure on children's lung function. Am J Respir Crit Care Med 2011; 184: 822-827.

24 Puckett JL, Taylor RW, Galant SP, et al. Impact of analysis interval on the multiple exhalation flow technique to partition exhaled nitric oxide. Pediatr Pulmonol 2010; 45: 182-191. 
Eckel S, Berhane K, Linn W, et al. Statistical methods for studying determinants of airway and alveolar nitric oxide. Am J Respir Crit Care Med 2013; 187: A5092.

26 Eckel SP, Linn WS, Berhane K, et al. Estimation of parameters in the two-compartment model for exhaled nitric oxide. PLoS One 2014; 9: e85471.

27 Högman M, Holmkvist T, Wegener T, et al. Extended NO analysis applied to patients with COPD, allergic asthma and allergic rhinitis. Respir Med 2002; 96: 24-30.

28 Akaike H. A new look at the statistical model identification. IEEE Trans Automat Contr 1974; 19: 716-723.

29 R Development Core Team. R: A Language and Environment for Statistical Computing. Vienna, R Foundation for Statistical Computing, 2013.

30 Modig L, Dahgam S, Wass K, et al. Effects of short-term exposure to air pollution on the levels of exhaled nitric oxide among adults - results from the ADONIX study in Gothenburg, Sweden. Eur Respir J 2012; 40: Suppl. 56, 609 s.

31 Steerenberg P, Snelder J, Fischer P, et al. Increased exhaled nitric oxide on days with high outdoor air pollution is of endogenous origin. Eur Respir J 1999; 13: 334-337.

32 Adamkiewicz G, Ebelt S, Syring M, et al. Association between air pollution exposure and exhaled nitric oxide in an elderly population. Thorax 2004; 59: 204-209.

33 Kubesch NJ, de Nazelle A, Westerdahl D, et al. Respiratory and inflammatory responses to short-term exposure to traffic-related air pollution with and without moderate physical activity. Occup Environ Med 2015; 72: $284-293$.

34 Penttinen $\mathrm{P}$, Timonen K, Tiittanen $\mathrm{P}$, et al. Ultrafine particles in urban air and respiratory health among adult asthmatics. Eur Respir J 2001; 17: 428-435.

35 Buonanno G, Marks GB, Morawska L. Health effects of daily airborne particle dose in children: direct association between personal dose and respiratory health effects. Environ Pollut 2013; 180: 246-250.

36 Cristescu S, Mandon J, Harren F, et al. Methods of NO detection in exhaled breath. J Breath Res 2013; 7: 017104.

37 Tsoukias NM, George SC. A two-compartment model of pulmonary nitric oxide exchange dynamics. $J$ Appl Physiol 1998; 85: 653-666.

38 Kharitonov S, Yates D, Robbins R, et al. Increased nitric oxide in exhaled air of asthmatic patients. Lancet 1994; 343: 133-135.

39 Piacentini GL, Bodini A, Vino L, et al. Influence of environmental concentrations of NO on the exhaled NO test. Am J Respir Crit Care Med 1998; 158: 1299-1301.

40 Gehring U, Oldenwening M, Brunekreef B, et al. The impact of ambient NO on online measurements of exhaled and nasal NO: the PIAMA study. Pediatr Allergy Immunol 2009; 20: 665-672.

41 Liu H-C, Hsu J-Y, Cheng Y-W, et al. Exhaled nitric oxide in a Taiwanese population: age and lung function as predicting factors. J Formos Med Assoc 2009; 108: 772-777.

42 Jöbsis Q, Schellekens S, Kroesbergen A, et al. Off-line sampling of exhaled air for nitric oxide measurement in children: methodological aspects. Eur Respir J 2001; 17: 898-903.

43 Baraldi E, Azzolin N, Dario C, et al. Effect of atmospheric nitric oxide (NO) on measurements of exhaled NO in asthmatic children. Pediatr Pulmonol 1998; 26: 30-34. 